\title{
Original
}

\section{PATHOLOGY OF RESPIRATORY TRACT IN FORMER WORKERS IN MUSTARD GAS FACTORY} A REVIEW

\section{Kouki Inai and Yukio Takeshima}

Second Department of Pathology, Hiroshima University School of Medicine

\begin{abstract}
Mustard Gas (MG), a potent carcinogen, has been elucidated to induce lung cancer, by means of long-term clinical observation in former workers in MG factory on Okunojima, Hiroshima prefecture. On this rare occasion, an opportunity to observe pulmonary carcinogenetic process in human was given. Histological research on bronchial epithelium revealed the presence of preneoplastic lesions including dysplasia and various types of hyperplastic or metaplastic lesions. Furthermore, recent progresses in research techniques on genetic abnormality have been applied to analyze specific genetic changes related to exposure to MG, in order to clarify multistep carcinogenesis of bronchial epithelium. The knowledge obtained through research of former workers in MG factory should prove useful to understand chemical carcinogenesis in humans. (J Toxicol Pathol $8: 343 \sim 353,1995$ )
\end{abstract}

Key words : Mustard gas, Lung cancer, Chronic bronchitis, Preneoplastic lesion, p53 gene

\section{Introduction}

On Okunojima, a small island in Hiroshima Prefecture, a poisonous gas factory established by the Japanese army had been operated from 1929 until 1945 (Fig. 1). Mustard gas (Bis (2chloroethyl) sulphide, $\beta \beta^{\prime}$-dichloroethyl sulphide,
Schwefel-Lost, S-lost, S mustard, sulphur mustard, sulphur mustard gas, yellow cross liquid, MG) was the main product. Also produced had been lewisite (chlorvinylarsine), diphenylcyanarsine (sneezing gas), hydrocyanic acid, phosgene, and chloracetophenone. This factory had a maximum ability to produce MG of 450 tons per month (Fig.

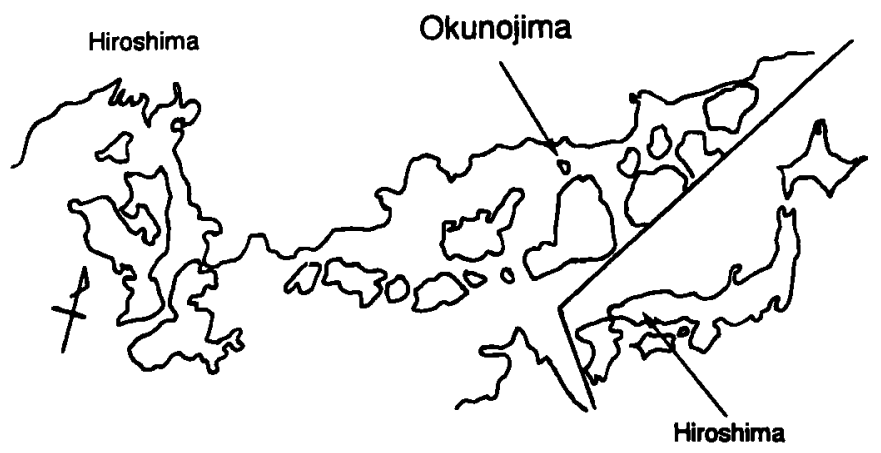

Fig. 1. Location of Okunojima in Hiroshima Prefecture.

井内康輝 武島幸男

Accepted for publication: August 20, 1995

Mailing address: Kouki Inai, Second Department of

Pathology, Hiroshima University School of Medicine, 1-2-

3, Kasumi, Minami-ku, Hiroshima 734, Japan. 
2). In the factory, most of the workers wore protective cloth and mask, but accidentally attached poison gases and repeatedly aspirated very small amounts of poisonous gas that could not be protected. Many workers were suffering from acute injuries including erosion and bulla formation of skin, and acute inflammation of respiratory tract $^{1,2}$ (Fig. 3 ).

The history of MG as a chemical weapon is long. During World War I, MG was first used in the battle field on the Western Front in 1914-1918 war on July 12-13, 1917. In this battle, about 160,000 British soldiers were treated for gas poi- soning. The clinical study reported that $80 \%$ of victims of MG poisoning had chronic bronchitis and significant excess of deaths attributed to cancer of the lung and pleura ${ }^{3}$. However, it was reported that among US veterans exposed to MG, there was no significant increase of lung cancer mortality, compared with the controls ${ }^{4}$. After World War I, the use of poisonous gas including MG had been forbidden by an international treaty, but the production of poisonous gas had been continued in many countries.

The epidemiologic study on the workers at British MG factory at Cherine, England, during

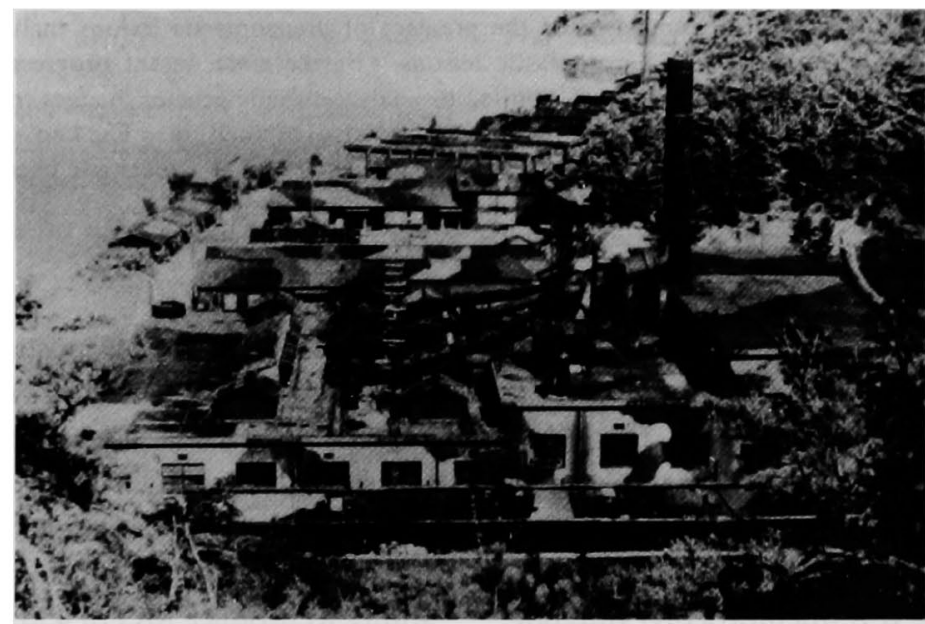

Fig. 2. Mustard gas factory on Okunojima, photographed after the end of World War II (Offered by Dr. Yukutake, the Director of Tadanoumi Hospital).

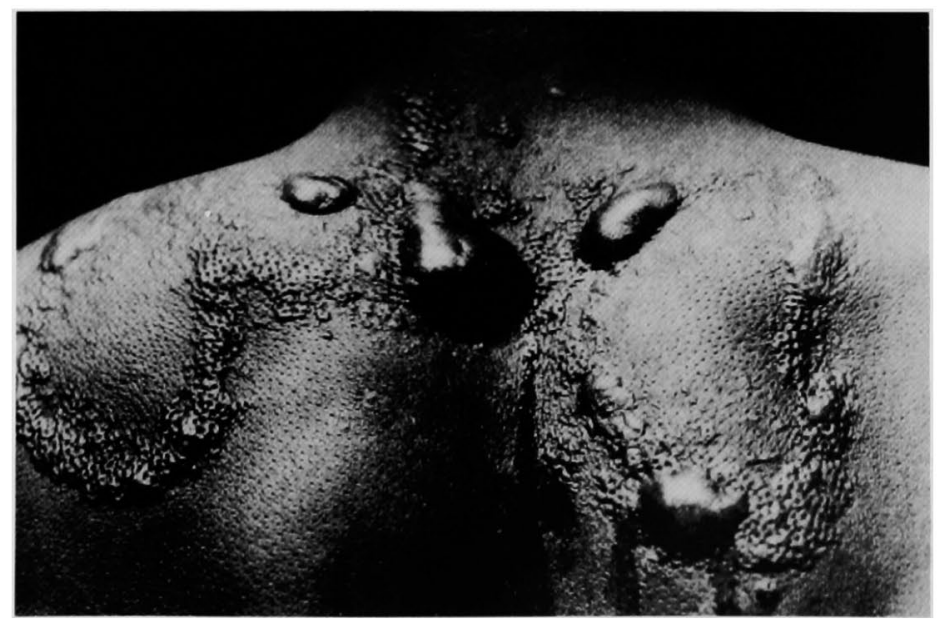

Fig. 3. Skin lesions of MG worker (Offered by Dr. Yukutake, the Director of Tadanoumi Hospital). 
World War II, showed strong evidences that exposure to MG could cause lung cancer and nonmalignant respiratory disease as well as cancers of esophagus and stomach ${ }^{5}$. In the case of German MG factory worker, it was reported that malignant tumor, especially bronchial carcinoma, bladder carcinoma, and leukemia occurred with significant rate of increase ${ }^{6}$.

After Word War II, most of the countries had abandoned to produce and keep poisonous gas, but a possibility of using poisonous gas at local wars still remains. During the Iran-Iraq war (1980-1988), Iraq used MG as a chemical weapon against Iran. In a clinical study of 535 Iranian patients exposed to MG, skin lesions (erythema, bulla, purpura, pigmentation, desquamation), and lesions of the eyes, lung, and gastrointestinal tract were demonstrated ${ }^{7}$. Eisenmenger et al. also reported the same clinical findings of Iranian victims transferred to Germany. Somani and Babu described the delayed disorders of MG on the respiratory tract among Iranian victims including chronic bronchitis, asthma, rhinopharyngitis, tracheobronchitis, laryngitis, recurrent pneumonia, and bronchiectasis ${ }^{8}$. Furthermore, Iraq armed forces also began a major military offensive against the Kurds on August 25, 1988, and on the occasion, MG gas was used in northern Iraq'.

\section{Toxicodynamics and Experimental Animal Car- cinogenicity Study of Mustard Gas}

Chemical and physical properties of MG are described as follows; Chemical formula of $M G$ is $\mathrm{C}_{4} \mathrm{H}_{8} \mathrm{Cl}_{2} \mathrm{~S}$ (Fig. 4). MG is colorless when pure, but normally a yellow oily liquid and forms prisms on cooling. It has a slight garlic-type odor. Molecular weight is 159.1. Melting point is 13-

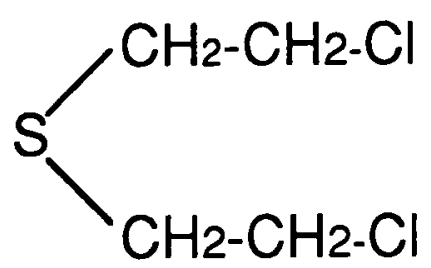

Fig. 4. Chemical structure of MG (I.A.R.C monograph, 1975). $14^{\circ} \mathrm{C}$ and boiling point $215-217^{\circ} \mathrm{C}$ as normal atmospheric pressure. MG is sparingly soluble in water, but soluble in fat, fat solvents, and other common organic solvents ${ }^{10}$.

The toxic effects of MG include inhibition of mitosis, nicotinamide adenine dinucleotide (NAD) depletion, decreased tissue respiration, and finally cell death. Most of the toxic effects are related to alkylation of DNA. Mustard gas is also selective in their accumulation in fat tissue, however, the effects of MG poisoning may be local, systemic, or both, depending on environmental conditions, exposed organs, and extent and duration of exposure ${ }^{11}$.

MG has also been reported to be a potent carcinogen as well as monofunctional and bifunctional DNA alkylating agent. It also alkylates RNA and proteins and produces DNA lesions, which may be repaired only at low doses. The sulfur mustards also alkylate the $\mathrm{O}^{6}$-position of guanine. DNA alkylation is likely to be primarily responsible for the mutagenic consequences of cellular exposure. The sulfur mustards induced a wide variety of genetic changes in many types of mammalian cells in vitro in a dose-related fashion including in vitro in peripheral blood lymphocyte at low dose ${ }^{12}$. $\mathrm{O}^{6}$-alkylguanine is repaired by $\mathrm{O}^{6}$-alkylguanine DNA alkyltransferase ${ }^{13}$, however, $\mathrm{O}^{6}$-ethylthioethyl guanine induced by $\mathrm{MG}$ was shown to be a poor substrate for this repair system $^{14}$. Possible toxicodynamics of MG are shown in figure 4. In contrast to mustard gas, the genetic toxicology of lewisite has not been fully studied. So far, there are no carcinogenicity, mutagenicity, and teratogenicity ${ }^{15}$.

As for animal carcinogenesis, nitrogen mustard, methyl bis (2-chloroethyl) amine hydrochloride had been mainly used experimentally instead of MG, because of its similar action. However, there are a few animal experiments using MG. MG, when injected subcutaneously into strains $\mathrm{C} 3 \mathrm{H}$, $\mathrm{C} 3 \mathrm{Hf}$, and A mice, induced neoplasms at the site of injection, as well as nitrogen mustard, injected subcutaneously into $\mathrm{C} 3 \mathrm{H}$ and $\mathrm{C} 3 \mathrm{Hf}$ mice. The neoplasms occurring at the site of injection were reported to be 11 sarcomas including fibrosarcoma, neurogenic sarcoma, and rhabdomyosarcoma, 3 papillomas, one squamous cell carcinoma, one 


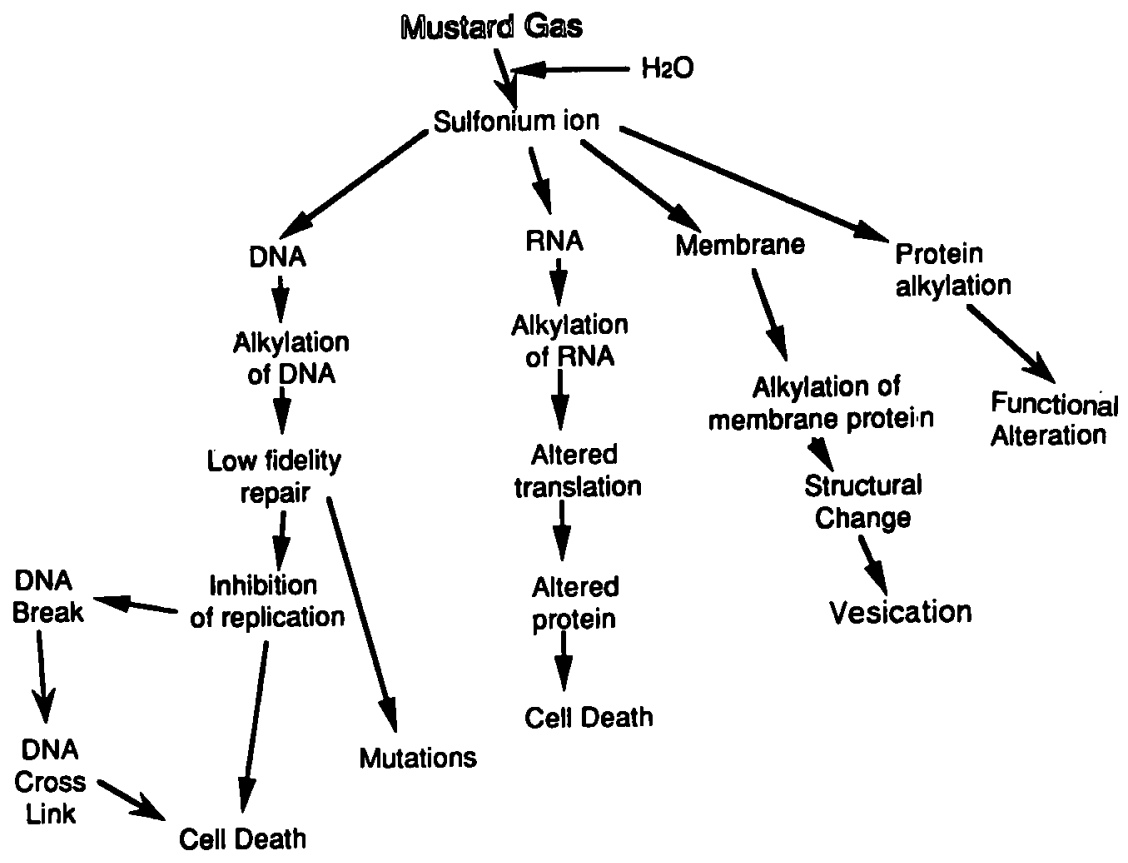

Fig. 5. Possible toxicodynamics of MG (modified from Somani and Babu, 1989).

hemangioendothelioma, and one breast carcinoma. Significant increase of lung tumors in $\mathrm{C} 3 \mathrm{H}$ and C3Hf mice injected subcutaneously with nitrogen mustard compared with controls was reported ${ }^{16}$. Intravenous injection of $\mathrm{MG}$ to strain $\mathrm{A}$ mice resulted in significant increase of lung tumors, compared with the control ${ }^{17}$. Induction of skin malignancy in rat by chamber test has been also reported ${ }^{18}$

\section{Clinical Research on Former Workers in Mustard} Gas Factory

Wada et al. described a summary observed among MG-exposed workers as follows. That is, among the 495 MG-exposed workers followed for

Table 1. Number of Malignant Neoplasms Observed in Former Workers in MG Factory (1952-1981)

\begin{tabular}{lcccr}
\hline \multicolumn{1}{c}{ Group } & A group & B group & C group & Total \\
\hline Number of survivors in 1952 & 761 & 705 & 602 & 2068 \\
& $(100)$ & $(100)$ & $(100)$ & $(100)$ \\
Total number of malignant & $140^{*}$ & 103 & 44 & 287 \\
neoplasms from 1952 to 1981 & $(18.4)^{* *}$ & $(14.6)$ & $(7.3)$ & $(13.9)$ \\
Respiratory system & 64 & 41 & 12 & 117 \\
& $(8.4)$ & $(5.8)$ & $(2)$ & $(5.7)$ \\
Digestive system & 71 & 51 & 28 & 150 \\
Others & $(9.3)$ & $(7.2)$ & $(4.7)$ & $(7.3)$ \\
& 16 & 14 & 5 & 35 \\
& $(2.1)$ & $(2)$ & $(0.8)$ & $(1.7)$ \\
\hline
\end{tabular}

A group : MG production, MG and Lewisite production, Lewisite production

B group : Laboratory, repair, inspection, incineration, and guard

C group : Tear gas, Sneezing gas and other gas production, desk work, medical doctor, and nurse

* Actual number, ** Incidence (\%) 


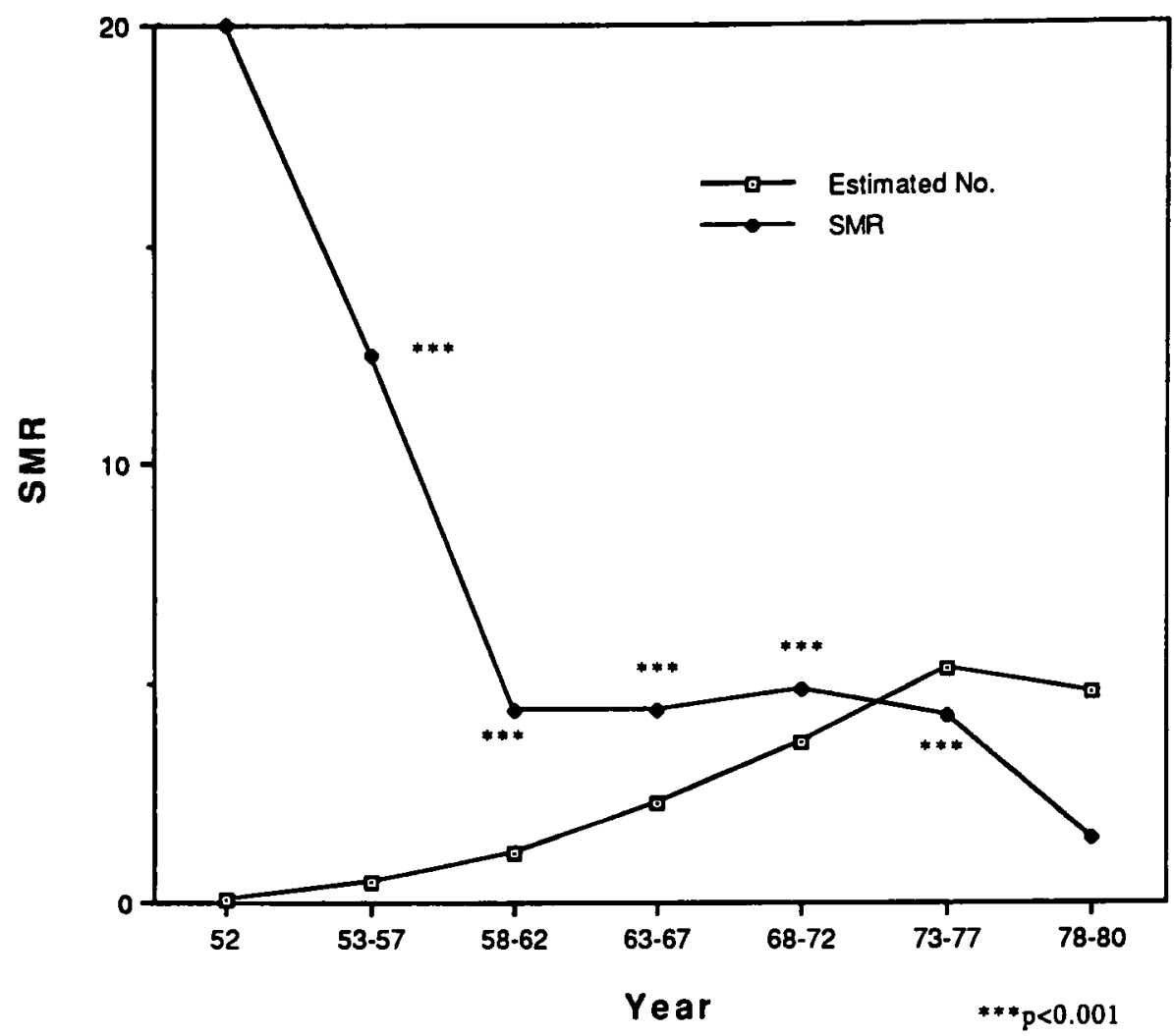

Fig. 6. Changes of standardized mortality ratio (SMR) of lung cancer in former workers in MG factory (1952-80) (Maeda, et al., 1994).

16 years, 33 deaths from cancer of the respiratory tract were observed, compared with the expected number of $0.9^{1}$. Furthermore, Nishimoto et al. presumed that the cancer of respiratory tract among MG-exposed workers was induced by exposure to MG and possible influence of smoking might be negligible ${ }^{19}$ (Table 1). In addition, it was reported that clinical symptoms of chronic bronchitis at heavily-MG-exposed workers were more severe than that at less-exposed workers and unexposed coworkers $^{20}$, and 55.5\% of these workers were suffering from chronic bronchitis ${ }^{21}$.

The latent period of lung cancer induced by exposure to MG was thought to be 10-33 years with an average of 22 years $^{22}$. Recently, Maeda et al. analyzed the clinicopathological features of 45 autopsied cases with lung cancer from 1952 to 1990. The lung cancer mortality rate until 1977 was significantly higher than that among the general population of Hiroshima prefecture, after adjusting the background mortality rate for sex, age, and year. However, this fact was not observed among the cases autopsied after $1977^{23}$ (Fig. 6). From these facts, it is suggested that lung cancers occurring until 1977 were only those induced by exposure to MG.

Pathological Research on Former Workers in Mustard Gas Factory

The comprehensive report by Yamada summarized the autopsy and biopsy cases examined pathologically during 1952-197424. There were 68 cancer cases among 102 MG-exposed workers examined (including 94 autopsy cases and 8 biopsy cases). Among cancer cases, 44 cases had cancers of the respiratory tract. The characteristic features of respiratory tract cancer in these 44 cases are as follows;

1. Most of carcinomas were located at the central portion of the lung, as well as upper airway such as paranasal sinus, larynx, pharynx, and 
Table 2. Autopsy Cases with Malignant Neoplasm among Former Workers in MG Factory (1952-1974)

\begin{tabular}{|c|c|}
\hline Total number autopsied & 102 \\
\hline \multirow{2}{*}{$\begin{array}{l}\text { Cases with malignant neoplasm } \\
\text { Cases with multiple malignant neoplasm }\end{array}$} & $68(66.7 \%)$ \\
\hline & $8(7.8 \%)$ \\
\hline \multicolumn{2}{|l|}{ Number of cases with malignant neoplasm } \\
\hline \multicolumn{2}{|l|}{ Respiratory system } \\
\hline Lung & 27 \\
\hline Pharynx & 3 \\
\hline Larynx & 8 \\
\hline Sinus & 3 \\
\hline Trachea & 2 \\
\hline Total & 44 (43.1\%) \\
\hline \multicolumn{2}{|l|}{ Digestive system } \\
\hline Stomach & 9 \\
\hline Liver & 2 \\
\hline Colon & 2 \\
\hline Esophagus & 3 \\
\hline Tongue & 1 \\
\hline Total & $17(16.7 \%)$ \\
\hline Urinary bladder & $1(0.9 \%)$ \\
\hline Thyroid gland & $2(1.9 \%)$ \\
\hline Skin & $2(1.9 \%)$ \\
\hline Lymph node & $2(4.3 \%)$ \\
\hline
\end{tabular}

trachea.

2. As to histopathological type of carcinoma, squamous cell carcinoma and small cell undifferentiated carcinoma occupied 70.3\%.

3. There were 8 cases with multiple cancers (Table 2).

On the other hand, Makihara conducted a pathoanatomical study on chronic bronchitis in MG-exposed workers ${ }^{25}$. He observed multiple sections of tracheo-bronchial trees (19 sections from each cases) from 25 MG-exposed cases (including 11 lung cancer cases and 14 non-lung cancer cases) and 53 non-MG-exposed cases (including 13 lung cancer cases and 40 non-lung cancer cases). As the result, respiratory tracts in all of the MG-exposed cases showed pathological features of chronic bronchitis including bronchial gland hypertrophy, thickening of basement membrane and inflammatory cell infiltration, congestion, edema, fibrosis, and thickening of elastic and muscle layer in the lamina propria, and the degrees among MG-exposed cases were more intense than that of non-exposed cases.

Kou analyzed goblet cell metaplasia of tracheo-bronchial epithelium among MG-exposed and non-MG-exposed autopsy cases $^{26}$. The frequency of goblet cell metaplasia was the highest in the group of MG exposed non-lung cancer group, although the frequency of goblet cell metaplasia were not correlated with Reid index in any of the groups.

Inai et al. examined mucus glycoprotein of goblet cells in tracheo-bronchial epithelium of MG-exposed cases compared to non-MG-exposed ones ${ }^{27}$. As the result, the proportion of case positive for PNA and SBA lectin binding in MG-exposed and/or lung cancer cases had a significant difference from non-MG-exposed nonlung cancer cases. This observation suggested a large heterogeneity in oligosaccharide chains of mucus glycoprotein, which resulted from its incomplete or abnormal synthesis. This abnormality was most likely to be related to the previous exposure carcinogen, including MG.

\section{Detection of Preneoplastic Lesion in Bronchial Epithelium}

By the fact that MG-exposed cases have a high risk of lung cancer, it has been supposed that histological findings of various steps on pulmonary carcinogenesis can be observed on the bronchial epithelium of MG exposed cases. Therefore, Tokuoka et al. performed total histological observation of bronchial tree using step-cut sections ${ }^{28}$. Using 66 male autopsy cases, composed of the group of 19 MG-exposed cases with lung cancer (MGLC), 17 MG-exposed cases with no lung cancer (MGNLC), 10 non-MG-exposed cases with lung cancer (LC), and 20 non-MG-exposed cases with no lung cancer (NLC). The tracheobronchial tree from distal trachea to third branch was serially cut transversely every $3-4 \mathrm{~mm}$ and all of the sections were prepared for histological observation. As the result, foci of moderate or severe atypical cellular lesions, that is, dysplasia, and carcinoma-in-situ (CIS) in total slides of each group, were counted as 146 in 3485 of MGLC, 72 in 2226 of MGNLC, 70 in 3797 of LC, and 18 in 
Table 3. Frequency of Atypical Lesions in the Tracheo-bronchial Epithelium in 66 Autopsied Cases

\begin{tabular}{lcccc}
\hline \multicolumn{1}{c}{ Group } & $\begin{array}{c}\text { No. of } \\
\text { tissue } \\
\text { slides }\end{array}$ & $\begin{array}{c}\text { No. of } \\
\text { atypical } \\
\text { lesions }\end{array}$ & $\begin{array}{c}\text { Rate } \\
(\%)\end{array}$ & $\begin{array}{c}\text { Test } \\
\text { (MG vs. } \\
\text { non-MG) }\end{array}$ \\
\hline $\begin{array}{l}\text { MG-exposed with } \\
\text { lung cancer }\end{array}$ & 3485 & 146 & 4.2 & \\
$\begin{array}{l}\text { Non-MG exposed } \\
\text { with lung cancer }\end{array}$ & 2226 & 72 & 3.2 & $\mathrm{p}<0.10$ \\
$\begin{array}{l}\text { MG-exposed with } \\
\text { no lung cancer }\end{array}$ & 3797 & 70 & 1.8 & \\
$\begin{array}{l}\text { non-MG exposed } \\
\text { with no lung cancer }\end{array}$ & 4611 & 18 & 0.4 & $\mathrm{p}<0.001$ \\
\hline
\end{tabular}

(Tokuoka, et al., 1986)

4611 of NLC, respectively (Table 3). The frequency of moderate or severe dysplasia and CIS in MGLC was the highest, and on the comparison between MG and non-MG cases showed significantly higher frequency in MG cases. A multivariate analysis revealed a significant correlation between the frequency of dysplasia and presence of MG-exposed history, though the frequency of dysplasia was also influenced significantly by age, smoking history, and pathological diagnosis of chronic bronchitis. Furthermore, the frequency of dysplasia was significantly higher in the cases of squamous cell carcinoma than those of other histological types, particularly small cell carcinoma. Also these foci of dysplasia were frequently observed around squamous cell carcinoma-in-situ and microinvasive squamous cell carcinoma ${ }^{29}$. Consequently, it was suggested that atypical cellular lesion (dysplasia) may be a preneoplastic lesion of squamous cell carcinoma.

A histological study was also performed to examine various types of hyperplastic lesions in the tracheo-bronchial epithelium of MG-exposed cases, using the same sections mentioned above, selected from $10 \mathrm{MG}$-exposed cases with no lung cancer and 15 non-MG-exposed cases with no lung cancer. Hyperplastic lesions of the tracheobronchial epithelium were divided into basal cell hyperplasia (polygonal cell type and spindle cell type), intermediated cell hyperplasia, and transitional metaplasia. In addition, two unique lesions, called as "intraepithelial cyst" and "flatunheaved columnar epithelial hyperplasia" by us, were observed. The frequency of all of these hyperplastic lesions in MG exposed cases with no lung cancer were significantly higher than that in non-MG-exposed cases with no lung cancer. One lesion called as "flat-unheaved columnar epithelial hyperplasia" was observed in the case of MGexposed case with non-lung cancer. A similar

Table 4. Frequency of Hyperplastic or Metaplastic Lesions in the Tracheobronchial Epithelium of 30 Autopsied Cases

\begin{tabular}{|c|c|c|c|c|c|}
\hline \multirow{2}{*}{ Lesions } & \multirow{2}{*}{ Degree } & \multicolumn{4}{|c|}{ Numbers of lesions (\%) } \\
\hline & & \multicolumn{2}{|c|}{$\begin{array}{l}\text { MG group } \\
\text { (2284 specimens) }\end{array}$} & \multicolumn{2}{|c|}{$\begin{array}{l}\text { Non-MG group } \\
\text { (3197 specimens) }\end{array}$} \\
\hline \multicolumn{6}{|l|}{ Basal cell hyperplasia } \\
\hline \multirow{3}{*}{ Polygonal cell type } & + & 875 & $(38.3)^{* *}$ & 700 & $(21.9)$ \\
\hline & \# & 203 & $(8.9)^{* *}$ & 97 & (3.1) \\
\hline & \# & 29 & $(1.3)^{* *}$ & 7 & $(0.2)$ \\
\hline \multirow[t]{3}{*}{ Spindle cell type } & + & 491 & $(21.5)^{*}$ & 569 & $(17.8)$ \\
\hline & $\#$ & 241 & $(10.6)^{* *}$ & 49 & (1.5) \\
\hline & 4 & 13 & $(0.6)^{* *}$ & 4 & $(0.1)$ \\
\hline Intermediate cell hyperplasia & & 343 & $(12)^{* *}$ & 77 & (2.4) \\
\hline Transitional metaplasia & & 192 & $(8)^{* *}$ & 123 & (3.8) \\
\hline Intraepithelial cyst & & 52 & $(2.2)^{* *}$ & 28 & $(0.9)$ \\
\hline $\begin{array}{l}\text { "Flat-unheaved columnar } \\
\text { epithelial hyperplasia" }\end{array}$ & & 1 & $(0.04)$ & 0 & (0) \\
\hline
\end{tabular}

* $\mathrm{P}<0.05, * * \mathrm{P}<0.01$ 
Table 5. p53 Mutation in Lung Cancer Related to MG Exposure

\begin{tabular}{|c|c|c|c|c|c|c|c|}
\hline $\begin{array}{l}\text { Case } \\
\text { no. }\end{array}$ & Age $^{1)}$ & Histology ${ }^{2)}$ & $\begin{array}{l}\text { Exposure } \\
\text { history }\end{array}$ & $\begin{array}{l}\text { Smoking } \\
\text { history }\end{array}$ & $\begin{array}{l}\text { Codon } \\
\text { change }\end{array}$ & $\begin{array}{l}\text { DNA base } \\
\text { change }\end{array}$ & $\begin{array}{l}\text { Amino acid } \\
\text { change }\end{array}$ \\
\hline \multicolumn{8}{|c|}{ MG-exposed cases } \\
\hline \multirow[t]{2}{*}{ MG 1} & 48 & Sm & $3 \times 35$ & 20 & 252 & $\mathrm{CTC}>\mathrm{CTT}$ & Silent \\
\hline & & & & & 254 & $\mathrm{ATC}>\mathrm{ATT}$ & Silent \\
\hline MG 2 & 62 & Sm & $3 \times 26$ & 24.8 & Wild type & & \\
\hline MG 3 & 83 & $\mathrm{Sm}$ & $3 \times 77$ & 37 & 244 & $\mathrm{GGC}>\mathrm{TGC}$ & Gly $>$ Cys \\
\hline MG 4 & 65 & Sm & $1 \times 20$ & 45 & Wild type & & \\
\hline MG 5 & 67 & Ad & $2 \times 11$ & 41 & Wild type & & \\
\hline MG 6 & 74 & Ad & $1 \times 15$ & 0.25 & Wild type & & \\
\hline MG 7 & 59 & Adsq & $1 \times 2$ & 80 & 263 & $A A T>A G T$ & Asn $>$ Ser \\
\hline MG 8 & 83 & Adsq & $1 \times 63$ & 13.3 & Wild type & & \\
\hline \multirow[t]{2}{*}{ MG 9} & 80 & Sq & $1 \times 80$ & 0 & 262 & GGT $>$ AGT & Gly $>$ Ser \\
\hline & & & & & 274 & $\mathrm{GTT}>\mathrm{ATT}$ & Val $>$ lle \\
\hline \multirow[t]{2}{*}{ MG10 } & 57 & $\mathrm{Sq}$ & $4 \times 35$ & 53 & $199-200$ & GGAAAT > GGAAT & Frameshift \\
\hline & & & & & (1 base del & on) & \\
\hline MG11 & 59 & $\mathrm{Sq}$ & $2 \times 45$ & 40 & Wild type & & \\
\hline \multirow[t]{2}{*}{ MG12 } & 60 & $\mathrm{Sq}$ & $1 \times 24$ & 28.5 & $274-275$ & GTTTGT > GTTGT & Frameshift \\
\hline & & & & & (1 base del & on) & \\
\hline \multicolumn{8}{|c|}{ Non-exposed cases } \\
\hline MN 1 & 87 & Sm & - & 36 & Wild type & & \\
\hline MN 2 & 72 & Sm & - & 9 & Wild type & & \\
\hline MN 3 & 78 & $\mathrm{Sm}$ & - & 28 & 173 & GTG $>$ ATG & Val $>$ Met \\
\hline MN 4 & 63 & Sm & - & 51 & 159 & $\mathrm{GCC}>\mathrm{CCC}$ & Ala $>$ Pro \\
\hline MN 5 & 63 & Ad & - & $?$ & Wild type & & \\
\hline MN 6 & 58 & $\mathrm{Sq}$ & - & $?$ & Wild type & & \\
\hline MN 7 & 66 & Adsq & - & $?$ & Wild type & & \\
\hline MN 8 & 88 & Ad & - & $?$ & 235 & $A A C>G A C$ & Asn $>$ Asp \\
\hline MN 9 & 74 & Ad & - & $?$ & 249 & AGG $>$ AGT & Arg $>$ Ser \\
\hline \multirow[t]{2}{*}{ MN10 } & 58 & Sq & - & 114 & $293-294$ & GGGGAG > GGGAG & Frameshift \\
\hline & & & & & \multicolumn{2}{|c|}{ ( 1 base deletion) } & \\
\hline MN11 & 71 & $\mathrm{Sq}$ & - & 45 & 245 & GGC $>$ AGC & Gly $>$ Ser \\
\hline MN 12 & 63 & $\mathrm{Sq}$ & - & 56 & Wild type & & \\
\hline
\end{tabular}

1) Age at diagnosis

2) Histology of lung cancer: sm, small cell carcinoma ; sq, squamous cell carcinoma ; ad, adenocarcinoma ; adsq, adenosquamous carcinoma

3) Type of work $\times$ working duration (month). Type of work : 1, Yperite (MG) production ; 2, Lewisite production ; 3. Laboratory, incineration, repair ; 4. Sneezing gas production

4) Pack-Years of cigarette smoking

5) Mutations on the non-transcribed strand are shown.

(Takeshima, et al., 1994)

result was obtained when the frequency was calculated at every branching number of respiratory tract. These findings suggest that $\mathrm{MG}$ played a role in forming hyperplastic lesions of tracheobronchial epithelium ${ }^{30}$ (Table 4). So far, it remains unclear whether these bronchial epithelial hyperplastic lesions are the early stage of dysplasia and carcinoma or not, but from the facts that in the MG-exposed cases, epithelial hyperplasia, dysplasia, and lung cancer were frequently observed in a similar distribution of bronchial tree, the sequential change from hyperplasia to dysplasia and carcinoma is highly suspected. 


\section{Genetic Abnormality in Lung Cancer of MG- exposed Cases}

Recently, research techniques on molecular biology have developed especially in the field of detection of abnormalities on oncogenes and suppressor oncogenes. The application of polymerase chain reaction (PCR) method has made a great contribution to this advance, especially when archival paraffin embedded materials are used. Mutation of the p53 suppressor oncogene is known to be detected in approximately half of all human cancers $^{31}$. This allows comparison of the mutational spectra of various cancer type. In vitro studies have showed that chemicals can produce distinctive mutational spectra, suggesting 'fingerprinting' of genetic damage. Molecular epidemiological studies have generated hypothesis linking environmental carcinogen exposure to human cancer. For example, a mutational hot spot in the third base of codon 249 was detected in hepatocellular carcinoma which is observed in the specific area with high incidence of liver cancer. In that area, people are infected with hepatitis B viruses and are exposed to high levels of dietary aflatoxin $\mathbf{B}_{1}{ }^{32,33}$. However, this type of mutation was uncommon in low-incidence areas where people are exposed to low level of aflatoxin $B_{1}$. A second example is the linkage between mutations at pyrimidine sites and UV radiation. The characteristics of p 53 mutation at this type of damage have been found in human skin cancer ${ }^{34-36}$. And it was reported that the mutational spectra at p53 gene of smoker's lung cancers were significantly different from those of non-smokers and probably related to carcinogens included in tobacco smoke ${ }^{31,37,38}$. These observations suggest that analyses of p53 gene mutational spectra provide us a clue to cancer etiology $y^{39-41}$.

p53 gene mutation was analyzed on 12 primary lung cancers from MG-exposed cases at Okunojima and 12 lung cancers as controls. Genomic DNA was isolated from archival paraffin-embedded tissues. Exon 5-8 were amplified by PCR using p53-specific primers, and sequenced by dideoxy termination methods. Six out of 12 lung cancers from MG workers contained a total of eight somatic point mutations : two cases had double $\mathrm{G}$ : $\mathrm{C}$ to $\mathrm{A}$ : $\mathrm{T}$ transitions ; one had a $\mathrm{G}: \mathrm{C}$ to $\mathrm{T}$ : $\mathrm{A}$ transversion; one had an $\mathrm{A}: \mathrm{T}$ to $G$ : $C$ transition; and two cases had single base deletions. Four of six mutations occurred on the non-transcribed, DNA coding strand. Out of 12 unexposed cases, there were six single base mutations in six cancers, and no double mutations was noted. The p53 mutational frequency in the MG-exposed case was similar to that in the nonexposed controls as well as the usual smokingrelated lung cancers reported previously. However, the distinctive double mutations ( $G$ : $C$ to $A$ : $T$ transition) observed in two cases were unusual and might be related to exposure to $\mathrm{MG}^{42}$.

It has been elucidated that the process of carcinogenesis is highly related to the accumulation of genetic abnormality. From the fact that a number of preneoplastic epithelial lesion was observed in relation with exposure to $M G$, it is expected that a specific abnormality of gene exists in the preneoplastic lesions. The methods included PCR-SSCP analysis and direct sequencing to detect p53 gene mutation and analysis of genomic instability using microsatellite polymorphism (CA repeat polymorphism) of $17 \mathrm{p} 13$ and $3 \mathrm{p} 21.3$. As the result, a part of columnar cell hyperplasia and severe hyperplasia showed genomic instability, although p53 mutation could not be detected. These facts suggest that genetic abnormality may occur at the early stage of pulmonary carcinogenesis by MG (unpublished data).

\section{Conclusion}

By means of long-term clinical observation on former workers in MG factory at Okunojima, occurrence of lung cancer with significantly higher rate, especially squamous cell carcinoma and small cell carcinoma, was demonstrated. Histological observation of carcinogenetic process revealed the presence of a preneoplastic lesion. Furthermore, analysis of specific genetic changes related to exposure to MG was performed. The knowledge obtained from these studies should prove useful for understanding chemical carcinogenesis in human.

Acknowledgement: This work was supported in part by a Grant-in-Aid from the Ministry of Educa- 
tion, Science and Culture of Japan and by N.C.I. (U.S.A.) contract No. NEC-4893-8-001.

\section{References}

1. Wada, S, Miyanishi, M, Nishimoto, Y, and Kambe, $\mathbf{S}$ and Miller, RW : Mustard gas as a cause of respiratory neoplasia in man. Lancet $i$ : 1161-1163, 1968.

2. Nishimoto, $Y$, Yamakido, M, Shigenobu, T, Yukutake, $M$ and Matsusaka, $S$ : Cancer of the respiratory tract observed in retired workers from a poison gas factory (in Japanese). Jpn J Cancer Chemother 13 : 1144-1148, 1986.

3. Case, RAM and Lea, AJ : Mustard gas poisoning, chronic bronchitis and lung cancer. An investigation into the possibility that poisoning by mustard gas in the 1914-18 war might be a factor in the production of neoplasia. Br J Prev Soc Med 9: 62$72,1955$.

4. Norman. JE Jr : Lung cancer mortality in world war I veterans with mustard-gas injury: 1919-1965. J Natl Cancer Inst 54: 31 I-317, 1975 .

5. Easton, DF and Doll JP : Cancers of the respiratory tract in mustard gas workers. $\mathrm{Br} \mathrm{J}$ Indust Med 45 652-659, 1988.

6. Weiss, A, and Weiss, B : Carcinogenesis due to mustard gas exposure in man (in German). Dtsch Med Wschr 100 : 919-923, 1975.

7. Momeni, Ali-Z, Enshaeih, S, Meghdahi, $\mathbf{M}$ and Amindjavaheri $\mathbf{M}$ : Skin manifestations of mustard gas. A clinical study of 535 patients exposed to mustard gas. Arch Dermatol 128 : 775-780, 1992.

8. Eisenmenger, $\mathbf{W}$, Drasch, G, von Clarmann, $M$, Kretschmer, E, Pharm, M. and Roider, G : Clinical and morphological findings on mustard gas [Bis (2chloroethyl) Sulfide] poisoning. J Foren Sci 36 1688-1698, 1991.

9. Hu, H, Cook-Deegan, R, and Shukri, A : The use of chemical weapons. Conducting an investigation using survey epidemiology. JAMA 262 : 640-643, 1989.

10. International Agency on the Research of Cancer. Some aziridines, N-, S- \& O- mustards and selenium. In : IARC monographs on the evaluation of carcinogenic risk of chemicals to man. 9 : 181-207, 1975.

11. Somani, SM and Babu, SR: Toxicodynamics of sulfur mustard. Int J Clin Pharmacol Ther Toxicol 27 : 419-435, 1989.

12. Pechura, CM and Rall, DP: The health effects of mustard gas and lewisite. In: Veterans at risk. National Academic Press, Washington D.C., 1993.

13. Olsson, $M$ and Lindahl, $T$ : Repair of alkylated DNA in Escherichia coli. Methyl group transfer from $\mathrm{O}^{6}$-methylguanine to a proteincysteine residue. J Biol Chem 255 : 10568-10571, 1980.

14. Ludlum, DB, Kent, $S$ and Mehta, RM : Formation of $\mathrm{O}^{6}$-ethylthioethylguanine in DNA by reaction with the sulfur mustard, chloroethyl sulpide, and its apparent lack of repair by $\mathrm{O}^{6}$-alkylguanine-DNA alkyltransferase. Carcinogenesis 7: 1203-1206, 1986.

15. Goldman, M, and Dacre, JC: Lewisite : its chemistry, toxicology and biological effects. Rev Environ Contamination Toxicol 110 : 75-115, 1989.

16. Heston, WE : Occurrence of tumors in mice injected subcutaneously with sulfur mustard and nitrogen mustard. J Natl Cancer Inst 14: 131-140, 1953

17. Heston, WE : Carcinogenic action of the mustard. J Natl Cancer Inst 11 : 415-423, 1950.

18. McNamara, BP, Owens EJ, Christensen, MK, Vocci, FJ, Ford, DF and Rozimarek, H. 1975. Toxicological basis for controlling levels of mustard in the experiment. In: Edgewood Arsenal Special Publication EP-SP-74030. Aberdeen Proving Ground, MD : U.S. Army Armament Command. Edgewood Arsenal Biomedical Laboratory, 1975.

19. Nishimoto, Y, Yamakido, M, Shigenobu, T, Onari, $\mathbf{K}$ and Yukutake, $\mathbf{M}$ : Long-term observation of poison gas workers with special reference to respiratory cancers. Sangyo Ika Daigaku Zasshi 5 supplement : 89-94, 1983.

20. Nishimoto, Y, Burrows, B, Miyanishi, M, Katsuta, S, Shigenobu, T, Kettel LJ : Chronic obstructive lung disease in Japanese poison gas workers. Am Rev Resp Dis 102 : 173-179, 1970.

21. Shigenobu, $\mathbf{T}$ : Clinical observations on retired workers of Okunojima poison gas factory, with special reference to chronic bronchitis (in Japanese). Med J Hiroshima Univ 21 : 409-499, 1973.

22. Nishimoto, $\mathrm{Y}$ : Occupational lung cancer with special reference to poisonous gas injuries (in Japanese). Nippon Nouson Igaku Zasshi 32: 1076-1085, 1984.

23. Maeda, A, Awaya, Y, Ihara, Y, Yoshida, Y, Ishioka, S, Inamizu, T, Yonehara, S, Inai, K, Shigenobu, T and Yamakido $M$ : A study of autopsied lung cancer cases among retired workers of the Okunojima poison gas factory (in Japanese). Lung Cancer 34 : 525-530, 1994.

24. Yamada, A : On the late injuries following occupational inhalation of mustard gas with special reference to carcinoma of the respiratory tract. Acta Pathol Jpn 13 : 131-155, 1963.

25. Makihara, H : Pathoanatomical studies on chronic bronchitis in patients exposed to mustard gas (in Japanese). Med J Hiroshima Univ 33 : 1127-1161, 1979.

26. Kou, E : Pathohistological studies on goblet cell metaplasia in the human bronchial epithelium (in Japanese). Med J Hiroshima Univ 33 : 1105-1128, 1985.

27. Inai, K, Kou, E, Nambu, S, and Tokuoka, S : Al altered lectin binding to mucus glycoprotein in goblet cells of human tracheobronchial epithelium among former mustard-gas workers. Acta Pathol Jpn 37 : 537-548, 1987.

28. Tokuoka, S, Hayashi, Y, Inai, K, Egawa, H, Aoki, Y, Akamizu, H, Eto, R, Nishida, T, Ohe, K, Kobuke, T, Nambu, S, Takemoto, T, Kou, E, Nishina, H, Fujihara, M, Yonehara, S, Tsuya, T, Suehiro, S and 
Horiuchi, $\mathrm{K}$ : Early cancer and related lesions in the bronchial epithelium in former workers of mustard gas factory. Acta Pathol Jpn 36 : 533-542, 1986.

29. Nambu, S: Histological studies on minute carcinomas and their parental lesions of the human bronchi (in Japanese). Med J Hiroshima Univ 34 : 109-155, 1986.

30. Takeshima, $\mathbf{Y}$, Inai, K, Kobuke, T, and Tokuoka, S : Histopathological former workers engaged in mustard gas factory. Med J Hiroshima Univ 38 : 853863, 1990.

31. Hollstein, M, Sidransky, D, Vogelstein, B, and Harris, CC : p53 mutations in human cancer. Science 253 : 49-53, 1991.

32. Hsu, IC, Metcalf, RA, Sun, T, Welsh, JA, Wang, NJ, and Harris, CC: Mutational hotspot in the p53 gene in human hepatocellular carcinoma. Nature 350 : 427-428, 1991.

33. Bressac, B, Kew, M, Wands, J, and Ozturk, M : Selective $G$ to $T$ mutations of $p 53$ gene in hepatocellular carcinoma from southern Africa. Nature 350 : 429-431, 1991.

34. Brash, DE, Rudolph, JA, Simon, JA, Lin, A, McKenna, GJ, Baden, HP, Halperin, AJ, and Ponten, J : A role for sunlight in skin cancer : UV induced p53 mutations in squamous cell carcinoma. Proc Natl Acad Sci USA 88 : 10124-10128, 1991.

35. Pierceall, WE, Mukhopadyway, T, Goldberg, LH, and Ananthasway, $\mathrm{HN}$ : Mutations in the p53 tumor suppressor gene in human cutaneous squamous cell carcinomas. Mol Carcinogenesis 4 : 445-449, 1991.

36. Rady, P, Scinicariello, F, Wagner, RFJr, and Tyring SK : p53 mutations in basal cell carcinomas. Cancer Res 52 : 3804-3806, 1992.

37. Suzuki, H, Takahashi, T, Kuroishi, T, Suyama, M, Ariyoshi, $Y$, and Ueda, $R$ : p 53 mutations in nonsmall cell lung cancer in Japan : association between mutations and smoking. Cancer Res 52 : 734-736, 1992.

38. Takeshima, Y, Seyama, T, Bennett, WP, Akiyama, $\mathrm{M}$, Tokuoka, S, Inai, K, Mabuchi, K, Land, CE, and Harris, CC: p53 mutations in lung cancers from non-smoking atomic-bomb survivors. Lancet 342 : 1520-1521, 1993.

39. Harris, CC: p53 : at the crossroads of molecular carcinogenesis and risk assessment. Science 262 : 1980-1981, 1993.

40. Harris, CC and Hollstein M : Clinical implications of the p53 tumor-suppressor gene. New Engl J Med 329 : 1318-1327, 1993.

41. Greenblatt, MS, Bennett, WP, Hollstein, M, and Harris, CC: Mutations in the p53 tumor suppressor gene : clues to cancer etiology and molecular pathogenesis. Cancer Res 54: 4855-4878, 1994.

42. Takeshima, $Y$, Inai, $K$, Bennett, PB, Metcalf, RA, Welsh, JA, Yonehara, S, Hayashi, Y, Fujihara, M, Yamakido, M, Akiyama, M, Tokuoka, S, Land, CE and Harris, $\mathrm{CC}$ : p53 mutations in lung cancer from Japanese mustard gas workers. Carcinogenesis 15 : 2075-2079, 1994. 